\title{
Application of Support Vector Machine and Finite Element Method to predict the mechanical properties of concrete
}

\author{
Aldemon L. Bonifácio ${ }^{a}$ \\ Julia C. Mendes ${ }^{b *}$ (D) \\ Michele C. R. Farage ${ }^{a}$ \\ Flavio S. Barbosa ${ }^{a}$ \\ Ciro B. Barbosaa \\ Anne-Lise Beaucour ${ }^{c}$ \\ ${ }^{\text {a }}$ Departamento de Mecânica Aplicada e Computacional, Universidade Federal de Juiz de Fora, Brasil. E-mails: \\ aldemon.bonifacio@engenharia.ufjf.br, michele.farage@ufjf.edu.br, flavio.barbosa@ufjf.edu.br, ciro.barbosa@ice.ufjf.br \\ ${ }^{b}$ Departamento de Engenharia Civil, Universidade Federal de Ouro Preto, Brasil. E-mail: julia.mendes@ufop.edu.br \\ c Département de Génie Civil, Université de Cergy-Pontoise, France. E-mail: anne-lise.beaucour@u-cergy.fr \\ *Corresponding author
}

https://doi.org/10.1590/1679-78255297

\begin{abstract}
Compressive strength and Young's modulus are the main properties used in the design of concrete structures. They are responsible for the cost, safety and dimensioning of the structure, and are generally measured in expensive and time-demanding tests. This fact encourages researches for fast and cost-effective methods to investigate the concrete's properties. Among the concrete types, structural Lightweight Aggregate Concrete (LWAC) is one of the most employed worldwide, but it presents limited studies and mix design techniques. Thus, this work evaluates and compares the performances of two methods to predict the compressive strength of LWAC samples: Support Vector Machine and Finite Element Method. To this end, both strategies use the LWAC's mix proportions and the Young's modulus, and the compressive strength of mortars and aggregates obtained from an experimental program from the literature. The results encourage further researches towards the development of a numerical tool that may assist engineers for practical purposes, since both methods show good agreement with the validation data.
\end{abstract}

\section{Keywords}

Lightweight Aggregate Concrete; Finite Element Method; Computational Intelligence; Support Vector Regression.

\section{Introduction}

Concrete is one of the most widely employed materials in the world. This composite comprises a matrix (the mortar - cement, fine aggregates and water) and a particulate solid phase (the coarse aggregates). When the concrete reaches a compressive strength $\left(f_{c}\right)$ higher than $20 \mathrm{MPa}$, it is considered structural concrete (ABNT, 2015). They can be classified according to their dry unit weight $(\rho)$ in lightweight $\left(\rho<2000 \mathrm{~kg} / \mathrm{m}^{3}\right)$, normal weight $\left(2000 \mathrm{~kg} / \mathrm{m}^{3}<\rho<2800 \mathrm{~kg} / \mathrm{m}^{3}\right)$ and 
heavyweight $\left(\rho>2800 \mathrm{~kg} / \mathrm{m}^{3}\right)$ (ABNT, 2015). Lightweight concrete can be achieved through foaming-inducing admixtures, air-entraining admixtures or using lightweight aggregates (LWA). In turn, lightweight aggregates (or lowdensity aggregates) are those with bulk density less than $1120 \mathrm{~kg} / \mathrm{m}^{3}$; e.g. pumice, volcanic cinders, tuff, expanded or sintered clay, shale, slate and vermiculite (ASTM, 2018).

Nowadays structural lightweight aggregate concrete (LWAC) is used on a large scale to reduce the self-weight of structures. In addition, it also presents transport advantages, allows longer spams, has thermoacoustic insulation properties, presents reduced autogenous shrinkage and a negligible interfacial transition zone due to internal curing (Mehta \& Monteiro, 2014) (Bentur et al., 2001). Differently from conventional concretes, in which the aggregate has a higher compressive strength than the mortar and the interfacial transition zone is the weak area of the composite; in LWAC, the aggregate strength is the main factor controlling the fracture of concrete (Zhang \& Gjvorv, 1991) (Yang \& Huang, 1998).

The compressive strength and static Young's Modulus of a concrete are amongst its most important mechanical properties, affecting the design, cost and safety of structures. These parameters are a direct function of cement type, water/cement ratio, aggregate type and the proportion of these ingredients, also called mix design. The mechanical properties are generally obtained by cost-demanding testing of concrete specimens after a standard curing period of 28 days, which means that 1 ) a significant amount of material must be spent for preparing the specimens and 2) only 28 days after poured into the structure they can be evaluated. This scenario is remarkably more sensitive for LWAC, from which there is not as many research projects and mix design techniques.

In this sense, several authors have been studying solutions to evaluate the concrete properties prior to its pouring, in order to avoid structural issues and material waste. Among these solutions, artificial intelligence algorithms have been used since the 2000s, especially the ones based on artificial neural networks (ANN) or support vector machines (SVM). For instance, Tenza-Abril et al. (2018), Sadrmomtazi et al. (2013), Gupta, Kewalramani e Goel (2006), Kim et al. (2005), Lee (2003), and Ni e Wang (2000) employed artificial neural networks with satisfactory performance; while Abd \& Abd (2017), Akande et al. (2014), Yan e Shi (2010), among others, studied support vector machine (SVM), reaching promising results. The results obtained from ANN or SVM have, in general, presented similar performances; and their reliability is proportional to the quantity and quality of training examples available.

Non-conventional concretes such as high-strength concrete (Cheng et al., 2012) (Gupta, 2007), lightweight foaming concrete (Abd \& Abd, 2017) and even geopolymer concrete (Nazari \& Sanjayan, 2015) have also been evaluated via SVM, but papers concerning LWAC are rather scarce.

Also, seeking to simulate the concrete behavior in complex civil engineering structures, the Finite Element Method (FEM) is extensively adopted. Fracture and damage are some of the main phenomena studied in the literature (Yu et al., 2010) (Al-Rub \& Kim, 2010) (Schlangen \& Van Mier, 1992), along with the application of these models for the investigation of reinforced concrete (Genikomsou \& Polak, 2015) (Hassan et al., 2015), concrete under fire conditions (Gao et al., 2013) (Ellobody \& Bailey, 2009), among others. Limited research was found, though, investigating the use of FEM models to predict the mechanical properties of lightweight concretes out of their raw materials. A relevant research involving this subject was carried out by Chung et al (2018), where a commercial FE package was used to evaluate mechanical and thermal properties of LWACs.

In this context, an import question emerges - which kind of methodology allows better prediction of the mechanical properties of LWACs: machine learning techniques or classical mechanical-based models? Therefore, seeking to improve the safety and contribute to the design of LWAC structures, the present work evaluates two methods to predict the compressive strength $\left(f_{c}\right)$ and Young's Modulus $\left(E_{c}\right)$ of this material from the characteristics of its mortar and aggregates. They are: Support Vector Machine with Regression (SVR) and Finite Element Method (FEM).

\section{Methodology}

\subsection{Finite Element Method}

In order to apply the Finite Element Method, LWAC was modeled as a biphasic material: the mortar $(m)$ and the lightweight aggregates $(a)$. The experimental data used as input and for validation were obtained from an experimental study with cylindrical samples of LWAC. The tests were performed by Ke et al. (2009) (2014), who analyzed compressive strength and modulus of elasticity of LWAC samples at 28 days. In this experimental program, three types of mortars were used: normal (40 MPa), high performance (64 MPa), and very high performance ( $86 \mathrm{MPa})$. Regarding the aggregates, five types were used: 0/4-650-A, 4/10-550-A, 4/10-430-A, 4/10-520-S and 4/8-750-S; in which each name matches the characteristic diameters $(\mathrm{d} / \mathrm{D}$, in $\mathrm{mm})$, the bulk density $\left(\mathrm{kg} / \mathrm{m}^{3}\right)$, and the type of aggregate $(A$ - expanded clay, S - expanded shale), respectively. The combination of these materials in proportions of $12.5 \%, 25.0 \%, 37.5 \%$ and 
45.0\% of LWA in volume generated 45 different formulations and over 180 specimens were tested. Each LWAC sample is also characterized by a water/cement factor, a quantity of cement, aggregate volume, aggregate density, Young's modulus and compressive strength.

From the aggregate and mortar properties we simulated the behavior of LWAC samples at 28 days when subjected to compressive load. The free processing software CAST3M was used, which includes built-in pre-processing and postprocessing tools. The parameters used in the FEM simulation were:

- Compressive strength $\left(f_{m}\right)$ and Young modulus $\left(E_{m}\right)$ of the mortar matrix (experimentally obtained by Ke et al. (2014));

- $\quad$ Tensile strength $\left(t_{m}\right)$ of the mortar, based on empirical correlations with its compressive strength proposed by Chust e Figueiredo Filho (2004);

- Volume fraction of lightweight aggregate adopted in the concrete's mixture (12.5\%, $25.0 \%, 37.5 \%$ and $45.0 \%)$;

- $\quad$ Particle size distribution of the aggregates (Ke, 2008);

- Young modulus of the LWA $\left(E_{a}\right)$, obtained empirically, based on its dry density (Ke et al., 2014);

- $\quad$ Compressive strength of the LWA $\left(f_{a}\right)$, obtained in an analytical inverse method by Ke et al. (2014).

- Tensile strength ( $\left.t_{a}\right)$ of the LWA, from (Ke et al., 2009);

- For comparison purposes, compressive strength $\left(f_{c, \text { exp }}\right)$ and Young modulus $\left(E_{c, \text { exp }}\right)$ measured on hardened LWAC samples (Ke et al., 2014).

The FEM model considers a longitudinal cross-section of a standard cylindrical sample with $16 \mathrm{~cm}$ of diameter and $32 \mathrm{~cm}$ high (Fig. 1a). For computational efficiency, 1/4 of the section was used in this work, considering the boundary conditions of geometric symmetry of the sample. In this specimen, the LWA were modelled as spheres randomly distributed within the homogeneous mortar matrix (Fig. 1b), with the same particle size distribution as the experimental program. In order to account for the dispersion of results, three models with random aggregate scattering (within the particle size distribution) were generated from each synthetic sample.

An elastoplastic material behavior was adopted for the FEM simulations, with Drucker-Prager yield criterion (Commissariat a l'Energie Atomic, 2003). Limits for compressive and tensile strength for each material were assumed according to the input parameters, and a perfect plastic yield was considered. The materials properties adopted for simulation and validation of these models are shown in Table 1.

To simulate the compressive strength test, a downward linear displacement of $0.5 \mathrm{~mm} / \mathrm{s}$ was imposed to the upper surface. The rate of 100 computational steps per 0.1 second was adopted. The compressive stress values were obtained from the support conditions at the base of the sample. The concrete is considered to reach failure at a $3.0 \%$ strain (Sussekind, 1985).

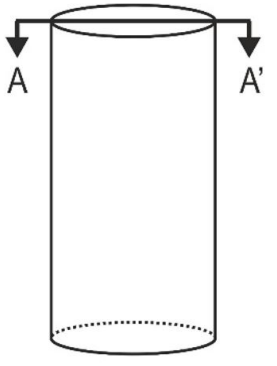

(a) Geometry of the modelled LWAC sample, from which a middle cross section was used

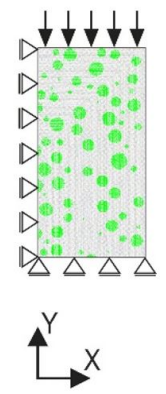

(b) Typical FE triangle mesh used; the round green circle representing the aggregate, surrounded by the mortar, in grey

Fig. 1 Numerical representation of one LWAC sample

Table 1 Summary of materials properties used in the FEM simulation

\begin{tabular}{ccccccc}
\hline Parameter & Description & Unit & Min & Max & Mean & Std. Dev. \\
\hline$E_{a}$ & LWA's Young's modulus & $\mathrm{GPa}$ & 5.89 & 30.29 & 12.48 & 6.83 \\
$E_{m}$ & Mortar's Young's modulus & $\mathrm{GPa}$ & 28.59 & 35.40 & 32.39 & 3.47 \\
\hline
\end{tabular}




\begin{tabular}{ccccccc}
$f_{a}$ & LWA's compressive strength & $\mathrm{MPa}$ & 14.80 & 75.90 & 29.39 & 14.93 \\
$f_{m}$ & Mortar's compressive strength & $\mathrm{MPa}$ & 40.18 & 85.96 & 63.44 & 22.90 \\
$t_{a}$ & LWA's tensile strength & $\mathrm{MPa}$ & 4.45 & 33.13 & 11.17 & 7.18 \\
$t_{m}$ & Mortar's tensile strength & $\mathrm{MPa}$ & 3.52 & 11.46 & 8.39 & 4.26 \\
Volume of Aggregate & - & $\%$ & 12.50 & 45.00 & 30.00 & 12.48 \\
$E_{c, \exp }$ & LWAC's Young's modulus & $\mathrm{GPa}$ & 15.67 & 34.21 & 24.50 & 5.06 \\
$f_{c, \text { exp }}$ & LWAC's compressive strength & $\mathrm{MPa}$ & 24.90 & 81.70 & 44.49 & 14.13 \\
\hline
\end{tabular}

\subsection{Support Vector Machine with Regression}

The models based on SVR method were applied to the set of experimental results for $12.5 \%, 25.0 \%, 37.5 \%$ and $45.0 \%$ volume of LWA (total of 180 mixtures of LWAC). From the total data, 2/3 were used to train the SVR model, and prediction results were obtained from the remaining 1/3. Four attributes were used as input variables: water/cement ratio, quantity of cement, volume of aggregate and density of aggregate; and two as output variables: LWAC's compressive strength $\left(f_{c}\right)$ and Young's modulus $\left(E_{c}\right)$. They are shown in Table 2.

Table 2 Summary of attributes used in the SVR evaluation

\begin{tabular}{ccccccc}
\hline Variable type & Parameter & Unit & Min & Max & Mean & Std. Dev. \\
\hline Input & Water/Cement ratio & - & 0.29 & 0.45 & 0.36 & 0.06 \\
& Quantity of Cement & $\mathrm{kg} / \mathrm{m} 3$ & 414.64 & 723.14 & 560.12 & 101.46 \\
& Volume of Aggregate & $\%$ & 12.50 & 45.00 & 29.73 & 12.41 \\
& Density of Aggregate ${ }^{2}\left(\times 10^{6}\right)$ & $\mathrm{kg}^{2} / \mathrm{m}^{6}$ & 3.18 & 36.00 & 11.10 & 12.80 \\
Output & $E_{c}$ & $\mathrm{GPa}$ & 16.22 & 33.63 & 24.73 & 4.93 \\
& $F_{c}$ & $\mathrm{MPa}$ & 26.25 & 79.85 & 44.60 & 14.32 \\
Validation & $E_{c, \text { exp }}$ & $\mathrm{GPa}$ & 15.12 & 35.07 & 24.60 & 5.07 \\
& $f_{c, \text { exp }}$ & $\mathrm{MPa}$ & 24.10 & 83.60 & 44.69 & 14.24 \\
\hline
\end{tabular}

To minimize bias associated with random data samples for training and testing, cross validation was applied by the k-folding technique. This method divides the total data set into k mutually exclusive subsets of the same size and, subsequently, a subset is used for testing and the remaining k-1 are employed to estimate the parameters, what allows for evaluating the accuracy of the model (Kohavi, 1995a). This process is performed k times alternating the test subsets. The k-fold technique is widely used in modeling problems concerning value prediction, such as the concrete properties (Chou \& Tsai, 2012) (Fushiki, 2011) (Chou et al., 2010).

In the present work, prediction methods were applied in a 10-fold cross-validation, which are favored from a computational standpoint (Kohavi, 1995b) (Fushiki, 2011). This procedure was repeated 100 times with a different test set each round, aiming to obtain dispersion results.

The parameters used to execute the SVR for output variable $f_{c}$ were: kernel is RBF (Radial Basis Function), $\mathrm{C}=100$ and $\gamma=0.03162278$; and for output variable $E_{c}$ were: kernel is RBF, $C=10$ and $\gamma=0.06309573$; where $C$ is the cost and $\gamma$ is the gamma. These parameters were optimized via grid search technique, which performs an exhaustive search to find the best setting to switch all input values (Chen et al., 2000).

For comparison purposes, besides SRV, three other supervised learning methods based on adjustment of parameters in a set experimental results were used. These are: Multiple Linear Regression (MLR), Quadratic Multiple Linear Regression (MR2) and Cubic Multiple Linear Regression (MR3). All the methods in this study were developed using the R software.

In addition, to evaluate the performance results, two different statistical parameters were employed: Root Mean Square Error (RMSE) and Mean Absolute Percentage Error (MAPE). They are mathematically defined by Equations 1 and 2, respectively, where $n$ is the number of samples, $y_{i}$ is the observed value and $p_{i}$ is the predicted value.

$$
\begin{aligned}
& R M S E=\sqrt{\frac{1}{n} \sum_{i=1}^{n}\left(y_{i}-p_{i}\right)^{2}} \\
& M A P E=\sqrt{\frac{1}{n} \sum_{i=1}^{n}\left(\left|\frac{y_{i}-p_{i}}{y_{i}}\right|\right)}
\end{aligned}
$$


The RMSE compares observed values with their predicted counterparts and calculates the average of the squared residual errors. However, the RMSE weights large errors more significantly. Alternatively, MAPE statistical metric is dimensionless and provides an effective means of residual error compared to each observed value with their respective predicted value. The lower the RMSE and MAPE values, the better the performance of the prediction model.

\section{Results}

\subsection{Finite Element Method}

In the FEM simulations, the compressive strength and Young's modulus were evaluated from 180 models (45 for each aggregate volume). In every step of computing time, the imposed displacement generates a stress increase in the elements of each phase (mortar and aggregates). Therefore, the stress developed in the elements can be normalized, according to each yield strength, in levels from 0 to 1 . This evolution can be followed in Fig. 2, which represents the tension levels related to deformations of $0.065 \%$ o, $0.34 \%$, $0.81 \%$, $1.10 \%$, $1.50 \%$ ond $3.00 \%$ o o a specimen with $12.5 \%$ of LWA type 4/10-550-A and normal mortar.

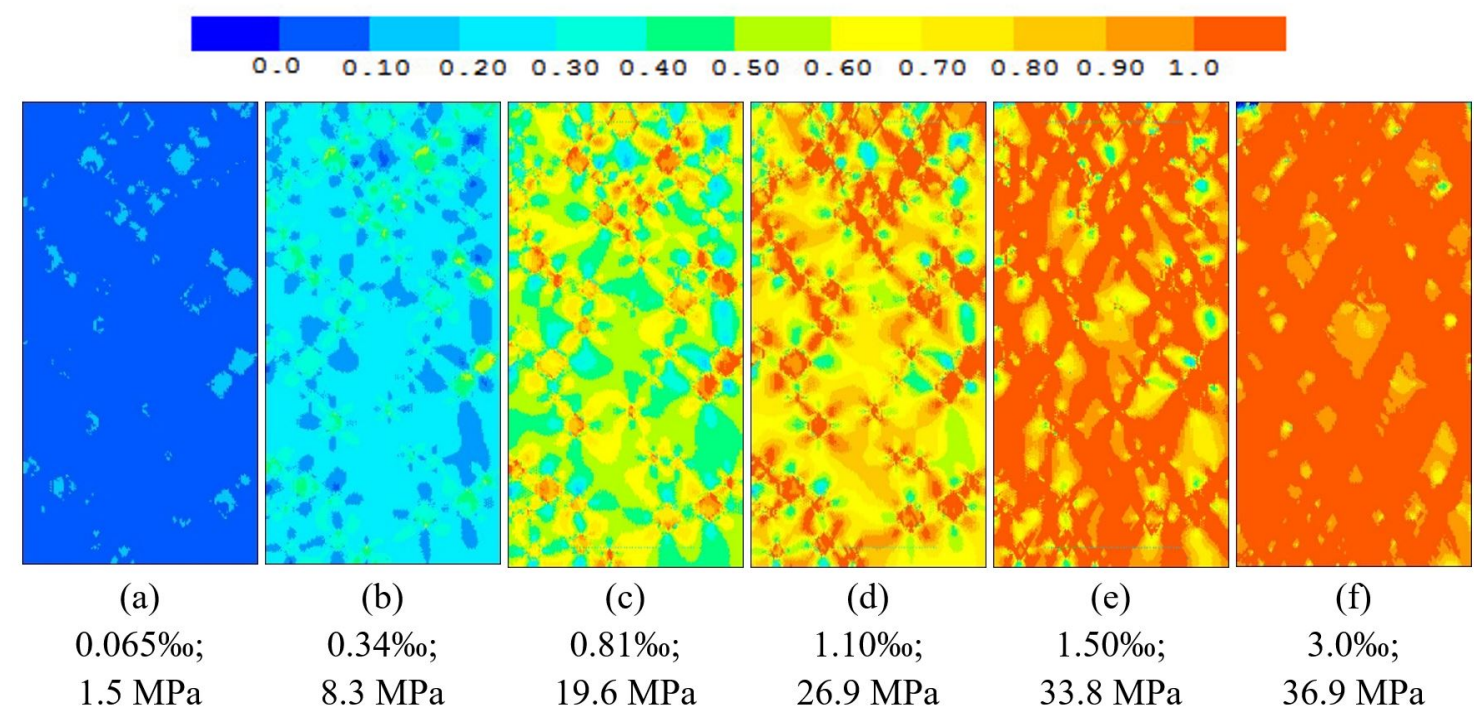

Fig. 2 Evolution of the stress levels in FEM simulations related to imposed displacement. Each material is standardized in accordance with their respective tensile and compressive strength.

In turn, the stress-strain curve of a LWAC sample with $12.5 \%$ of LWA type 4/10-550-A is shown in Fig. 3, along with the isolated curves from its mortar and aggregates. It can be seen from Fig. 3 that for strains up to approximately $1.3 \%$, the LWAC behavior is elastic, and Fig. 2a, Fig. 2b, Fig. $2 \mathrm{c}$ and Fig. $2 \mathrm{~d}$ show the evolution of the stress levels in this phase. At strains from $1.3 \%$ to $2.5 \%$, there is a transitional phase (Fig. 2e) and after $2.5 \%$, the specimen has reached the yield point that remains constant until the end of imposed displacement. Fig. $2 \mathrm{f}$ shows the final configuration assumed for the imposed displacement, when most elements have reached their yield strength. 


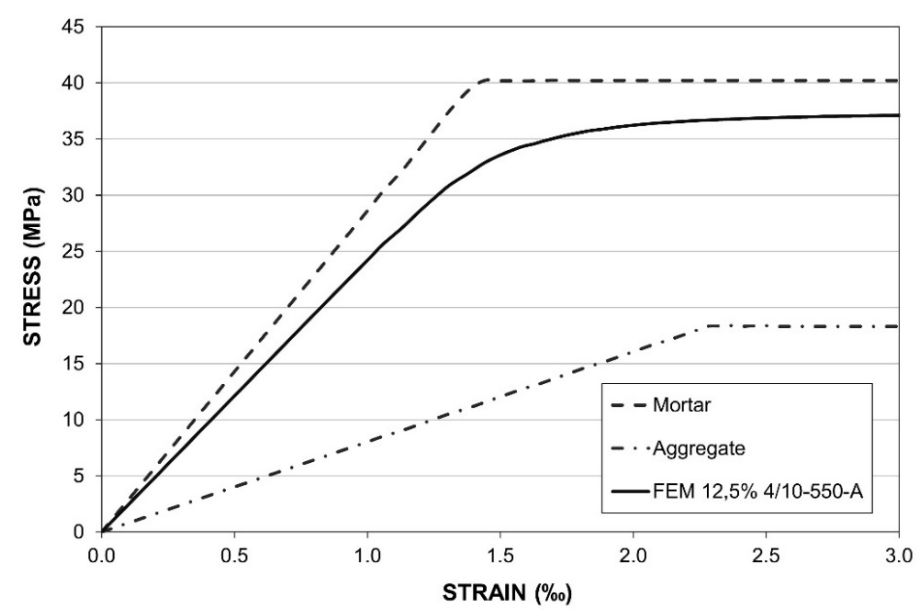

Fig. 3 FEM results of stress-strain curve of a sample with $12.5 \%$ of LWA type 4/10-550-A with normal mortar, along with the isolated curves from its mortar and aggregates

The simulation results for all LWAC models are summarized in Table 3, which includes minimum and maximum values, mean values, and the mean of relative variations from reference parameters (represented by the MAPE value). The results obtained are close to the experimental reference: the larger mean deviation found for $f_{c}$ was $7.25 \%$. On the other hand, the $E_{c}$ simulations presented results more similar to the experimental values, with mean deviation lower than $3.32 \%$. No bias was detected regarding the increasing volume of aggregate.

Table 3 Results of compressive strength $\left(f_{c}\right)$ and Young's modulus $\left(E_{c}\right)$ obtained from FEM simulations and relative variation to the experimental reference

\begin{tabular}{|c|c|c|c|c|c|c|}
\hline Property & $\begin{array}{l}\text { Volume of } \\
\text { Aggregate }\end{array}$ & Min & Max & Mean & St. Dev. & MAPE \\
\hline \multirow[t]{4}{*}{$f_{c}(\mathrm{MPa})$} & $12.5 \%$ & 33.30 & 84.39 & 54.37 & 15.90 & $5.70 \%$ \\
\hline & $25.0 \%$ & 28.59 & 81.50 & 47.05 & 14.52 & $7.25 \%$ \\
\hline & $37.5 \%$ & 24.25 & 78.84 & 41.16 & 14.15 & $7.05 \%$ \\
\hline & $45.0 \%$ & 23.01 & 76.33 & 38.58 & 13.49 & $6.02 \%$ \\
\hline \multirow[t]{4}{*}{$E_{c}(\mathrm{GPa})$} & $12.5 \%$ & 23.83 & 34.62 & 28.34 & 3.10 & $2.77 \%$ \\
\hline & $25.0 \%$ & 20.09 & 33.85 & 25.11 & 3.75 & $2.30 \%$ \\
\hline & $37.5 \%$ & 16.03 & 32.92 & 21.78 & 4.65 & $3.27 \%$ \\
\hline & $45.0 \%$ & 14.61 & 33.00 & 20.25 & 5.00 & $3.32 \%$ \\
\hline
\end{tabular}

The fact that LWA are already approximately rounded, thus similar to the model adopted for the aggregate phase, possibly contributed to the positive results. Although within a satisfactory range, the deviations observed are probably a function of the simplicity of model regarding the behavior of the materials, the reliability and significance of the experimental methods used to obtain the input parameters from the materials, and the heterogeneous nature of real concrete specimens (Lamond \& Pielert, 2006). Since the fracture mechanism close to the material yield stress is a more complex and cascading phenomenon, it is understandable that the numerical simulation obtained better results in the predictions regarding the initial elastic phase of the LWAC model $\left(E_{c}\right)$.

In addition, the experimental procedure for $E_{c}$ requires a significant larger effort in terms of time, cost and specimens than testing for $f_{c}$. In this sense, the FEM simulation can contribute to speeding up laboratory results in the development of new mix designs. Finally, the results obtained from FEM also allow extrapolation of these concrete models to more complex structures such as beams, slabs, sealing elements, among others, in order to simulate real world phenomena.

Table 4 shows the residual errors for the FEM simulations. It is observed that the results' dispersion is comparable to that obtained in laboratory experiments, which denotes the adequacy of the numerical procedures for practical purposes. Furthermore, Fig. 4 display residual errors histograms with a high degree of symmetry for each output variable, indicating that they are correspond to a noise. 
Table 4 Residual errors of prediction for 180 simulations for FEM.

\begin{tabular}{ccccc}
\hline Property & Min & Max & Mean & St. Dev. \\
\hline$f_{c}(\mathrm{MPa})$ & -6.99 & 5.19 & -0.81 & 3.02 \\
$E_{c}(\mathrm{GPa})$ & -0.41 & 2.04 & 0.63 & 0.51 \\
\hline
\end{tabular}

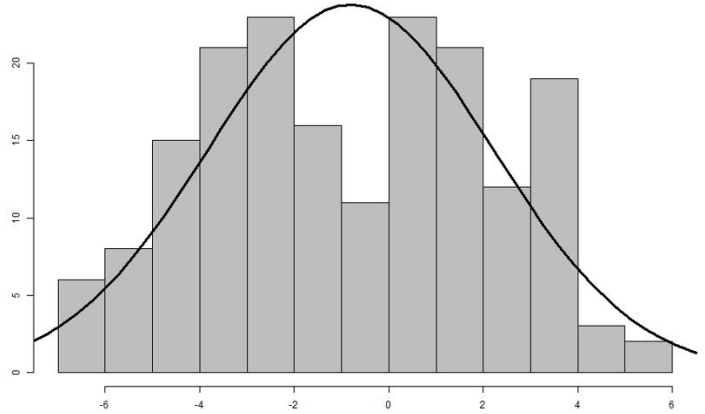

(a) Compressive Strength $\left(f_{c}\right)$

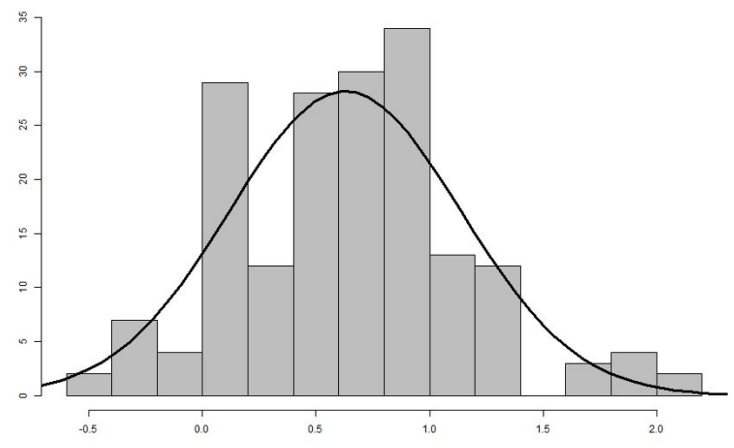

(b) Young's Modulus $\left(E_{c}\right)$

Fig. 4 Residual errors histogram for 180 simulations for FEM.

\subsection{Support Vector Machine with Regression}

The result of SVR predictions obtained from 100 runs of 10 -fold technique with all experimental data can be seen in Table 5. Table 6 shows the relative variations (predicted versus experimental) from two statistic metrics of results obtained with SVR, MLR, MR2 and MR3.

Table 5 Results of compressive strength $\left(f_{c}\right)$ and Young's modulus $\left(E_{c}\right)$ obtained from SVR simulations and relative variation to the experimental reference

\begin{tabular}{|c|c|c|c|c|c|c|}
\hline Property & $\begin{array}{l}\text { Volume of } \\
\text { Aggregate }\end{array}$ & Min & Max & Mean & St. Dev. & MAPE \\
\hline \multirow[t]{4}{*}{$f_{c}(\mathrm{MPa})$} & $12.5 \%$ & 37.68 & 79.85 & 56.49 & 15.08 & $3.78 \%$ \\
\hline & $25.0 \%$ & 31.01 & 58.05 & 40.12 & 10.24 & $5.13 \%$ \\
\hline & $37.5 \%$ & 28.13 & 57.02 & 40.61 & 7.42 & $7.37 \%$ \\
\hline & $45.0 \%$ & 26.25 & 71.86 & 37.44 & 12.37 & $5.57 \%$ \\
\hline \multirow[t]{4}{*}{$E_{c}(\mathrm{GPa})$} & $12.5 \%$ & 24.70 & 32.19 & 28.81 & 2.36 & $2.29 \%$ \\
\hline & $25.0 \%$ & 20.92 & 33.63 & 26.14 & 3.19 & $2.15 \%$ \\
\hline & $37.5 \%$ & 17.56 & 32.98 & 23.61 & 5.06 & $1.86 \%$ \\
\hline & $45.0 \%$ & 16.22 & 32.27 & 20.71 & 4.57 & $3.63 \%$ \\
\hline
\end{tabular}

Table 6 Comparison of the relative variations of the prediction of compressive strength $\left(f_{c}\right)$ and Young's modulus $\left(E_{c}\right)$ obtained with SVR, MLR, MR2 and MR3.

\begin{tabular}{ccccccc}
\hline Parameter & Statistic Metric & Method & Mean & St. Dev. & Min & Max \\
\hline$f_{c}$ & RMSE & SVR & $\underline{2.2578}$ & 1.7434 & 0.0058 & 12.0961 \\
& & MLR & 5.6020 & 4.0892 & 0.0010 & 19.2462 \\
& & MR2 & 2.5447 & 1.9575 & 0.0046 & 10.5498 \\
& & MR3 & 2.3613 & 1.8267 & 0.0045 & 14.0224 \\
& MAPE & SVR & $\underline{4.5307}$ & 0.7762 & 2.0935 & 6.9712 \\
& & MLR & 11.4736 & 1.7407 & 6.9306 & 17.6609 \\
& & MR2 & 5.5637 & 0.8458 & 3.0924 & 9.0049 \\
& & MR3 & 4.8982 & 0.7761 & 2.7108 & 7.6125 \\
& & SVR & $\underline{0.6543}$ & 0.4894 & 0.0006 & 2.9151 \\
& RMSE & MLR & 1.5076 & 1.1132 & 0.0026 & 5.8847 \\
\hline
\end{tabular}




$\begin{array}{cccccc} & \text { MR2 } & 0.6736 & 0.0522 & 0.0006 & 2.9719 \\ \text { MAPE } & \text { MR3 } & 0.6544 & 0.4971 & 0.0003 & 2.9751 \\ & \text { SVR } & \underline{2.4283} & 0.3797 & 1.4979 & 3.8771 \\ & \text { MLR } & 5.1204 & 0.7521 & 3.2081 & 7.4988 \\ & \text { MR2 } & 2.5225 & 0.3946 & 1.4684 & 3.9651 \\ & \text { MR3 } & 2.4391 & 0.3898 & 1.3602 & 4.0558\end{array}$

It can be seen from Table 5 that the SVR results are also close to the experimental references: the mean deviation of $f_{c}$ was below $7.4 \%$ and for $E_{c}$, lower than $3.63 \%$. Again, the increasing volume of aggregate did not explicitly influence the results. The small discrepancy is possibly due to minor adjustments issues regarding the prediction model (kernel, $\mathrm{C}$ e $y$ parameters) and the limitations of data used as training. In addition, care must be taken in seeking excessive error minimization, as overfitting could bring limitations to the prediction model, which could lose its ability to predict data different from those used in this study.

It can be observed that the values obtained by MR2 and MR3 methods were significantly better than the MLR method, since the lower the RMSE and MAPE, the better the result. Therefore, it can be concluded that there is nonlinearity between each input variable to the output variables, what reinforces the choice of the SRV technique.

Finally, it can be seen from Table 7 that the minimum and maximum values of residual errors of prediction have no discrepancy and no bias for both output variables. Furthermore, Fig. 5 shows a high degree of symmetry of the residual errors for each output variable, indicating that they are similar to a noise.

Table 7 Residual errors of prediction for 100 runs of 10 -fold for SVR.

\begin{tabular}{ccccc}
\hline Property & Min & Max & Mean & St. Dev. \\
\hline$f_{c}(\mathrm{MPa})$ & -7.43 & 8.60 & 2.67 & 0.02 \\
$E_{c}(\mathrm{GPa})$ & -2.19 & 2.32 & 0.02 & 0.74 \\
\hline
\end{tabular}

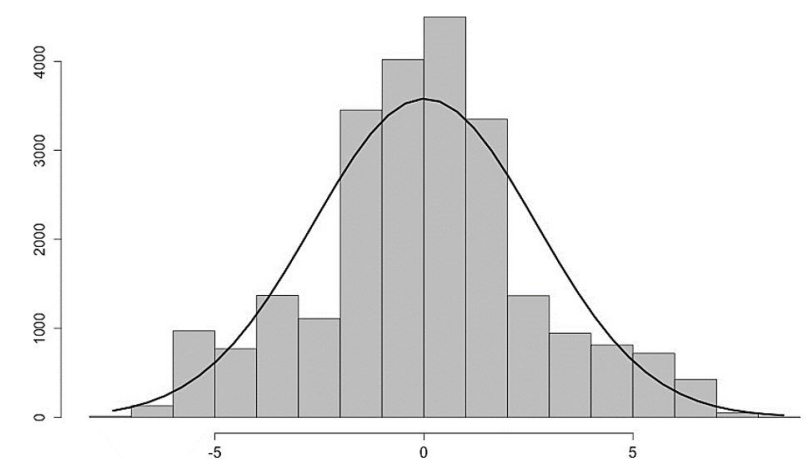

(a) Compressive Strength $\left(f_{c}\right)$

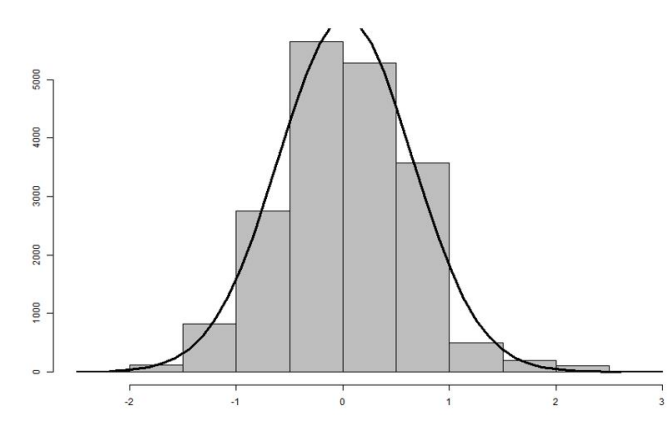

(b) Young's Modulus $\left(E_{c}\right)$

Fig. 5 Residual errors histogram for 100 runs of 10 -fold for SVR.

\section{Discussions and Conclusions}

In this study, two techniques for predicting the mechanical properties of Lightweight Aggregate Concrete (LWAC) have been developed and compared. The mechanical properties of interest were the compressive strength $\left(f_{c}\right)$ and static Young's Modulus $\left(E_{c}\right)$. The Finite Element Method (FEM) technique sought to reproduce computationally, through a 2-phase model, laboratory tests for these mechanical properties. In turn, the Support Vector Machine with Regression (SRV) technique is based on parameter settings to a set of experimental results, i.e. a supervised learning technique.

The advantages of the SVM to predict the concrete properties are its speed and the possibility for continuous re-training with new information. On the other hand, this technique requires a comprehensive amount of input data to be reliable. Regarding FEM, although slower, the method does not require previous final results. It provides satisfactory predictions with fewer inputs, given that the computational models are suitably constructed.

In order to better compare both techniques, Fig. 6 and Fig. 7 present a summary of all achieved results, by applying FEM and SVM, respectively. These figures exhibit experimental data on the horizontal axis and mean numerical results on the vertical axis. It is possible to observe that both techniques allow predictions for $f_{c}$ and $E_{c}$ that may be considered 
as identical for design purposes. These results allow us to answer the question highlighted in the Introduction of this paper (retyped): "which kind of methodology allows better prediction of the mechanical properties of LWAC: machine learning techniques or classical mechanical-based models?" The answer is: both.

Both techniques of computer modeling and computational intelligence showed good agreement with the experimental reference. SVR presented slightly better performance in predicting the mechanical properties of LWAC, with average deviations from the experimental values of $5.46 \%$ for $f_{c}$ and $2.48 \%$ for $E_{c}$. These results are lower than the $6.55 \%$ and $2.91 \%$ obtained by FEM for $f_{c}$ and $E_{c}$, respectively. The deviations of up to $7.25 \%$ for $f_{c}$ in the FEM model can be justified by the simplifications assumed in the modeling of the sample and the reliability of the input parameters. Alternatively, the deviations up to $7.37 \%$ on the SRV analysis are possibly due to minor adjustments issues regarding the prediction model and the data used. Overall, the SVR technique showed a lower average error compared to the FEM technique and both presented a better prediction of the $E_{c}$ than the $f_{c}$. This is expected, since the $E_{c}$ is obtained in the initial elastic stage of the specimens and is thus less subjected to intricate failure mechanisms and the consequences of random heterogeneities.

The two different statistical parameters used - RMSE and MAPE - yielded a comprehensive comparison of the prediction methods employed. The comparison among SVR, MLR, MR2 and MR3 confirm that the LWAC prediction problem is nonlinear and thus cannot be solved by traditional linear regression techniques (e.g. MLR). According to the methodology adopted, the best method of computational intelligence to predict the mechanical properties of LWAC is SVR, with an average MAPE of $4.5 \%$ and $2.4 \%$ for $f_{c}$ and $E_{c}$, respectively; and average RMSE of $2.3 \%$ and $0.7 \%$ for $f_{c}$ and $E_{c}$, respectively.

In summary, both FEM and SVR were technically feasible to estimate the compressive strength and modulus of elasticity of LWAC with minor deviations. Considering that experimental procedures for obtaining these properties require a significant amount of time, cost and materials, these methods can contribute to a more safe, economic and sustainable design of concrete mixtures.
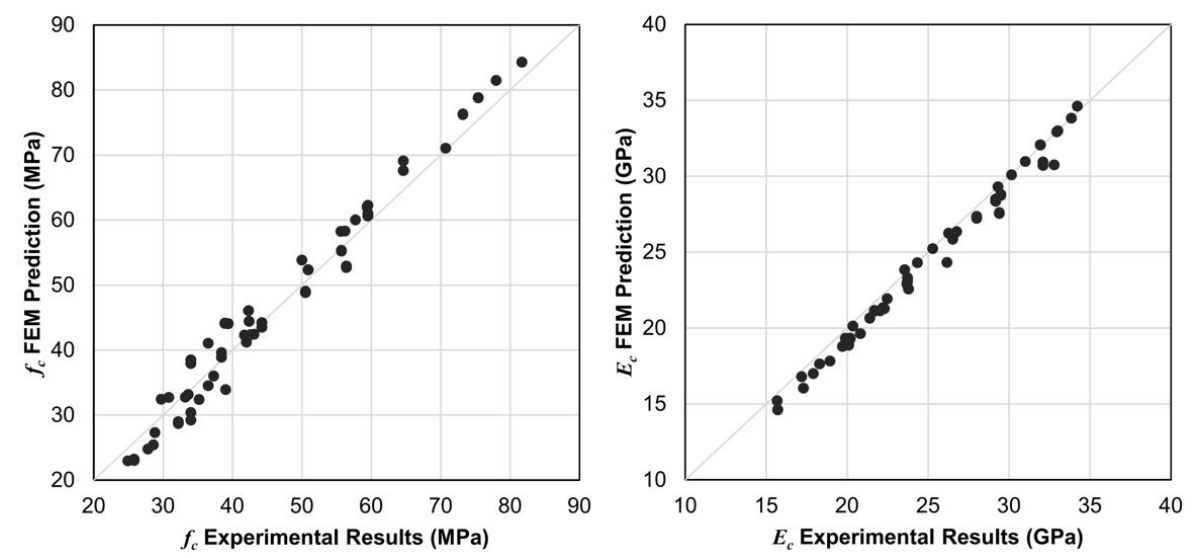

Fig. 6 Comparison between experimental and predicted FEM results

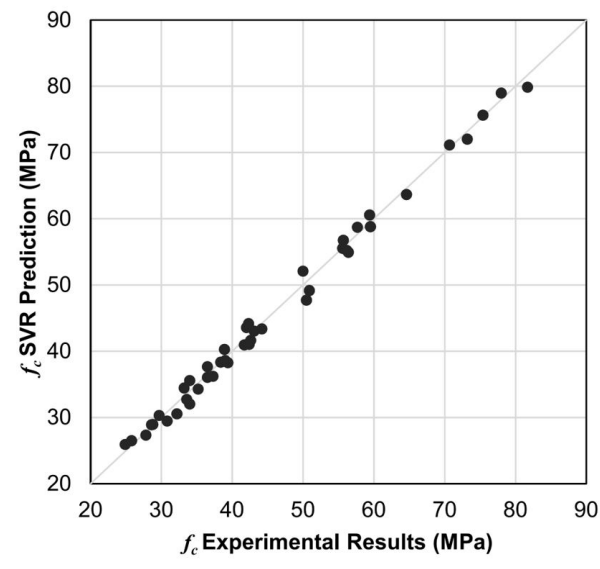

(a) Compressive Strength $\left(f_{c}\right)$

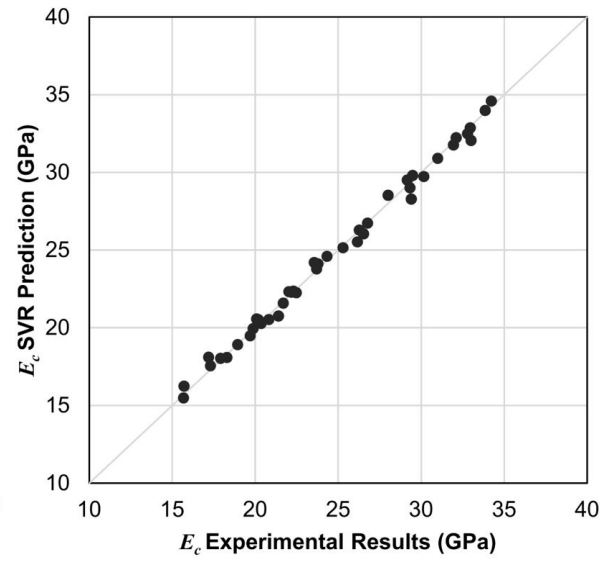

(b) Young's Modulus $\left(E_{c}\right)$

Fig. 7 Comparison between experimental and predicted SVR results 


\section{Acknowledgments}

The authors gratefully acknowledge CAPES (Coordenação de Aperfeiçoamento de Pessoal de Nível Superior), FAPEMIG (Fundação de Amparo à Pesquisa do Estado de Minas Gerais), CNPq (Conselho Nacional de Desenvolvimento Científico e Tecnológico), UFJF (Universidade Federal de Juiz de Fora), and UFOP (Universidade Federal de Ouro Preto) for providing infrastructure and financial support.

Author's Contributions: Conceptualization, FS Barbosa and MCR Farage; Methodology, AL Bonifacio and JC Mendes; Investigation, AL Bonifacio and JC Mendes; Writing - original draft, AL Bonifacio and JC Mendes; Writing - review \& editing, JC Mendes, FS Barbosa and MCR Farage; Funding acquisition, FS Barbosa and MCR Farage; Resources, AL Beaucour; Software, AL Bonifacio, JC Mendes and CB Barbosa; Supervision, FS Barbosa and MCR Farage.

Editor: Adnan Ibrahimbegovic; Paulo de Mattos Pimenta.

\section{References}

Abd, A. M. \& Abd, S. M., 2017. Modelling the strength of lightweight foamed concrete using support vector machine (SVM). Case studies in construction materials, Volume 6, pp. 8-15.

ABNT, 2015. NBR 8953 - Concrete for structural use - Density, strength and consistence classification, Rio de Janeiro: Associação Brasileira de Normas Técnicas.

Akande, K. O., Owolabi, T. O., Twaha, S. \& Olatunji, S. O., 2014. Performance comparison of SVM and ANN in predicting compressive strength of concrete. IOSR Journal of Computer Engineering, 16(5), pp. 88-94.

Al-Rub, R. K. A. \& Kim, S. M., 2010. Computational applications of a coupled plasticity-damage constitutive model for simulating plain concrete fracture. Engineering Fracture Mechanics, 77(10), pp. 1577-1603.

ASTM, 2018. ASTM C125 - Standard Terminology Relating to Concrete and Concrete Aggregates, West Conshohocken: ASTM International.

Bentur, A., Igarashi, S. I. \& Kovler, K., 2001. Prevention of autogenous shrinkage in high-strength concrete by internal curing using wet lightweight aggregates. Cement and concrete research, 31(11), pp. 1587-1591.

Chen, D. et al., 2000. Grid search as applied to the determination of Mark-Houwink parameters. Journal of applied polymer science, 76(4), pp. 481-487.

Cheng, M. Y., Chou, J. S., Roy, A. F. \& Wu, Y. W., 2012. High-performance concrete compressive strength prediction using timeweighted evolutionary fuzzy support vector machines inference model. Automation in Construction, Volume 28, pp. 106-115.

Chou, J. S., Chiu, C. K., Farfoura, M. \& Al-Taharwa, I., 2010. Optimizing the prediction accuracy of concrete compressive strength based on a comparison of data-mining techniques. Journal of Computing in Civil Engineering, 25(3), pp. $242-253$.

Chou, J. S. \& Tsai, C. F., 2012. Concrete compressive strength analysis using a combined classification and regression technique. Automation in Construction, Volume 24, pp. 52-60.

Chung, S. Y., Elrahman, M. A., Stephan, D. \& Kamm, P. H., 2018. The influence of different concrete additions on the properties of lightweight concrete evaluated using experimental and numerical approaches. Construction \& Building Materials, Volume 189, pp. 314-322.

Chust, C. R. \& Figueiredo Filho, J. R., 2004. Cálculo e Detalhamento de Estruturas Usuais de Concreto armado. São Carlos: Editora da UFSCar.

Commissariat a l'Energie Atomic, 2003. Notices / cast3m - mode. [Online] Available at: http://wwwcast3m.cea.fr/index.php?page=notices\&notice=MODE [Accessed 1507 2018].

Ellobody, E. \& Bailey, C. G., 2009. Modelling of unbonded post-tensioned concrete slabs under fire conditions. Fire Safety Journal, 44(2), pp. 159-167.

Fushiki, T., 2011. Estimation of prediction error by using K-fold cross-validation. Statistics and Computing, 21(2), pp. 137-146.

Gao, W. Y., Dai, J. G. T. J. G. \& Chen, G. M., 2013. Finite element modeling of reinforced concrete beams exposed to fire. Engineering structures, Volume 52, pp. 488-501. 
Genikomsou, A. S. \& Polak, M. A., 2015. Finite element analysis of punching shear of concrete slabs using damaged plasticity model in ABAQUS. Engineering Structures, Volume 98, pp. 38-48.

Gupta, R., Kewalramani, M. A. \& Goel, A., 2006. Prediction of concrete strength using neural-expert system. Journal of materials in civil engineering, 18(3), pp. 462-466.

Gupta, S. M., 2007. Support vector machines based modelling of concrete strength. World Academy of Science, Engineering and Technology, Volume 36, pp. 305-311.

Hassan, N. Z., Sherif, A. G. \& Zamarawy, A. H., 2015. Finite element analysis of reinforced concrete beams with opening strengthened using FRP. Ain Shams Engineering Journal.

Ke, Y., 2008. Caractérisation du comportement mécanique des bétons de granulats légers: expérience, Cergy: University of CergyPontoise.

Ke, Y. et al., 2009. Influence of volume fraction and characteristics of lightweight aggregates on the mechanical properties of concrete. Construction and Building Materials, 23(8), pp. 2821-2828.

Ke, Y., Ortola, S., Beaucour, A. L. \& Dumontet, H., 2014. Micro-stress analysis and identification of lightweight aggregate's failure strength by micromechanical modeling. Mechanics of Materials, Volume 68, pp. 176-192.

Kim, D. K., Lee, J. J., Lee, J. H. \& Chang, S. K., 2005. Application of probabilistic neural networks for prediction of concrete strength. Journal of Materials in Civil Engineering, 17(3), pp. 353-362.

Kohavi, R., 1995a. The power of decision tables. Berlin, Springer, pp. 174-189.

Kohavi, R., 1995b. A study of cross-validation and bootstrap for accuracy estimation and model selection. s.l., Morgan Kaufmann Publishers Inc., p. 1137-1143.

Lamond, J. F. \& Pielert, J. H., 2006. Significance of tests and properties of concrete and concrete-making materials. West Conshohocken: ASTM International.

Lee, S. C., 2003. Prediction of concrete strength using artificial neural networks. Engineering Structures, 25(7), pp. 849-857.

Mehta, P. \& Monteiro, P. J. M., 2014. Concrete: Microstructure, Properties, and Materials. 2a ed. São Paulo: IBRACON.

Nazari, A. \& Sanjayan, J. G., 2015. Modelling of compressive strength of geopolymer paste, mortar and concrete by optimized support vector machine. Ceramics International, 41(9), pp. 12164-12177.

Ni, H. G. \& Wang, J. Z., 2000. Prediction of compressive strength of concrete by neural networks. Cement and Concrete Research, 30(8), pp. 1245-1250.

Sadrmomtazi, A., Sobhani, J. \& Mirgozar, M. A., 2013. Modeling compressive strength of EPS lightweight concrete using regression, neural network and ANFIS. Construction and Building Materials, Volume 42, pp. 205-216.

Schlangen, E. \& Van Mier, J. G. M., 1992. Simple lattice model for numerical simulation of fracture of concrete materials and structures. Materials and Structures, 25(9), pp. 534-542.

Sussekind, J., 1985. Curso de concreto, Volume 1. Porto Alegre: Editora Globo.

Tenza-Abril, A. J., Villacampa, Y., Solak, A. M. \& Baeza-Brotons, F., 2018. Prediction and sensitivity analysis of compressive strength in segregated lightweight concrete based on artificial neural network using ultrasonic pulse velocity. Construction and Building Materials, Volume 189, pp. 1173-1183.

Yang, C. C. \& Huang, R., 1998. Approximate strength of lightweight aggregate using micromechanics method. Advanced Cement Based Materials, 7(3-4), pp. 133-138.

Yan, K. \& Shi, C., 2010. Prediction of elastic modulus of normal and high strength concrete by support vector machine. Construction and building materials, 24(8), pp. 1479-1485.

Yu, T. T. J. G., Teng, J. G., Wong, Y. L. \& Dong, S. L., 2010. Finite element modeling of confined concrete-I: Drucker-Prager type plasticity model. Engineering Structures, 32(3), pp. 665-679.

Zhang, M. H. \& Gjvorv, O. E., 1991. Mechanical properties of high-strength lightweight concrete. ACI Materials Journal, 88(3), pp. 240-247. 